\title{
Is PEGylated G-CSF superior to G-CSF in patients with breast cancer receiving chemotherapy? A systematic review and meta-analysis
}

\author{
Xiang $\mathrm{Li}^{1} \cdot$ Huan Zheng ${ }^{2} \cdot$ Man-Cheng $\mathrm{Yu}^{1}{ }^{1}$ (D) Wei Wang ${ }^{1} \cdot$ Xin-Hong $\mathrm{Wu}^{1} \cdot$ Dong-Mei Yang ${ }^{1} \cdot$ Juan $\mathrm{Xu}^{1}$
}

Received: 17 April 2020 / Accepted: 25 June 2020 / Published online: 3 July 2020

(C) Springer-Verlag GmbH Germany, part of Springer Nature 2020

\begin{abstract}
Background PEGylated granulocyte colony-stimulating factor (G-CSF) is a safe alternative to G-CSF to improve chemotherapyinduced neutropenia (CIN). This superiority has resulted in its increased use by physicians; however, the superiority of PEGylated G-CSF for CIN in breast cancer has not been conclusively determined.

Objectives To assess the superiority of PEGylated G-CSF for CIN in breast cancer in terms of effectiveness and safety via a systematic review and meta-analysis.

Methods A literature search in PubMed, Embase, Cochrane Library, and Web of Science was performed for eligible studies published from database inception to December 2019. All studies comparing PEGylated G-CSF and G-CSF for CIN of breast cancer were reviewed. After literature selection, data extraction and quality assessment were performed by two reviewers independently. Meta-analysis was conducted using Revman, version 5.2.

Results Nine randomized controlled trials were finally identified. The publication bias of these studies was acceptable. For the endpoint of effectiveness, analysis of the incidence/duration of grade $\geq 3$ neutropenia, the duration of grade 4 neutropenia, the incidence of febrile neutropenia (FN), and the time to absolute neutrophil count recovery showed no advantage of PEGylated GCSF over G-CSF for CIN of breast cancer $(P>0.05)$, with the premise of a sufficient dose of G-CSF according to the guidelines. No significant differences in grade 4 adverse events were observed between the groups $(P=0.29)$, and PEGylated G-CSF did not increase the incidence of skeletal and/or muscle pain compared with G-CSF $(P=0.32)$.

Conclusion PEGylated G-CSF was as effective and safe as G-CSF to reduce CIN in breast cancer but did not show an obvious superiority. However, in clinical practice, PEGylated G-CSF has an obvious advantage in terms of convenience, which could improve patient's quality of life.
\end{abstract}

Keywords PEGylated G-CSF · G-CSF · Breast cancer · Chemotherapy

\section{Introduction}

Although treatments for breast cancer, which is one of the most common cancers diagnosed in women [1], are

Xiang Li and Huan Zheng contributed equally to this work.

Man-Cheng Yu

774242785@qq.com

1 Department of Breast Surgery, Hubei Cancer Hospital, Tongji Medical College, Huazhong University of Science and Technology, Wuhan 430079, Hubei, People's Republic of China

2 Department of Neurology, Wuchang Hospital Affiliated to Wuhan University of Science and Technology, Wuhan 430063, Hubei, People's Republic of China continuously progressing, chemotherapy still plays a critical role. As early as 1995 , a study showed that chemotherapy dose had a marked influence on the treatment effect [2], and further studies found that a sufficient dosage and course of chemotherapy could significantly improve the relapse-free survival and overall survival of patients with breast cancer $[3,4]$. However, the toxicities caused by chemotherapy can obviously affect patients' tolerance and limit the sustained relative dose intensity (RDI) of chemotherapy, which can reduce the dosage and/or the course of chemotherapy, resulting in reducing effectiveness. Among the toxicities of chemotherapy, myelosuppression is a frequent reason for dose limitation and dose reduction in patients with cancer [5]. Moreover, once severe bone marrow suppression occurs, febrile neutropenia (FN) can be life-threatening, with a high risk of mortality. Therefore, clinical researchers have been exploring effective 
therapeutic drugs to alleviate chemotherapy-induced neutropenia $(\mathrm{CIN})$ and improve patients' tolerance of chemotherapy.

Granulocyte colony-stimulating factor (G-CSF) is one of the many cytokines that can simulate the proliferation and differentiation of neutrophil precursors and enhance the function of mature neutrophils [6]. As a result, since 1991, the first G-CSF (filgrastim) was approved for use in patients with cancer being treated with chemotherapy [7]. G-CSF-type therapeutic agents were widely used in the clinic to reduce CIN and were accepted in different clinical guidelines for patients receiving high FN chemotherapy regimens $[8,9]$. However, because of its primary clearance through the kidney, human G-CSF shows a short half-life, requiring daily administration intravenously or subcutaneously, which means patients suffer increased rates of injection site infection and display reduced tolerance $[10,11]$. To extend the half-life, polyethylene glycol (PEG) was introduced into G-CSF (PEGylated G-CSF), which changed the drugs' method of clearance, resulting in a decrease in the systemic clearance of the PEGylated form and a single dose showed efficacy comparable to that of daily injections of normal G-CSF [12, 13]. Compared with the GCSF, PEGylated G-CSF has benefits in terms of fewer injections, better compliance, and decreased burden for healthcare professionals and patients in various tumors or non-Hodgkin's lymphoma (NHL) [14]. However, Hendler et al. [15, 16] found that both forms of G-CSF could reduce the rate of FN and improve the safety and cost of chemotherapy but found no difference between them, especially in patients with breast cancer. Many studies have shown direct comparative data between PEGylated G-CSF and G-CSF; however, there was no agreement on whether PEGylated G-CSF was better than G-CSF in terms of safety and effectiveness in patients with breast cancer $[13,17]$. Therefore, we conducted a systematic review and meta-analysis to capture the available data on the effectiveness and safety of PEGylated G-CSF and G-CSF to compare their prophylaxis of $\mathrm{CIN}$ and $\mathrm{FN}$ during chemotherapy for breast cancer.

\section{Methods}

\section{Eligibility criteria and study selection}

Eligible studies must only compare PEGylated G-CSF and GCSF to improve CIN in patients with breast cancer and all the studies must be the randomized controlled trials (RCTs), with or without a blinding method. Only peer-reviewed articles with full text available were included. PEGylated C-CSF includes different long-acting PEG conjugates of a short-acting G-CSF, which could increase the plasma half-life. G-CSF refers to all kinds of G-CSF used in chemotherapy. Studies comparing PEGylated G-CSF and G-CSF for other types of cancers or non-RCTs were excluded. Duplicate studies and those with incomplete data were excluded, and when publications were duplicates, the latest studies were included. Studies were restricted to those in the English language and those enrolling adult patients.

\section{Information sources and search strategy}

Relevant studies were searched in the PubMed, Embase, Cochrane Library, and Web of Science databases, from the date of inception of the databases to December 2019. Two people independently searched the databases with combined Medical Subject Headings (MeSH) and unlimited words. The search words were as follows: breast cancer, breast tumor/ tumor, breast carcinoma, malignant neoplasm of breast, mammary cancer/tumor/carcinoma; PEGylated granulocyte colony stimulating, PEGylated G-CSF, PEG-rhG-CSF, PEG-G-CSF, pegfilgrastim, long-acting G-CSF; granulocyte colonystimulating factor, G-CSF, rhG-CSF, filgrastim, Neupogen, r-metHuG-CSF, Lenograstim, Zarxio, and so on; and the study types were searched using "randomized controlled trial," "RCT," and "randomized/randomized." We also screened all of the cited articles and related articles and contacted the authors by email if the articles were not available in full text.

\section{Data collection process}

All relevant published data were extracted. Papers were excluded if they did not report neutropenia-related outcomes. If the study used many different doses of PEGylated G-CSF, we collected the data related to the recognized effective dose, such as $6 \mathrm{mg}$ or $100 \mu \mathrm{g} / \mathrm{kg}$; however, if they disclosed data for both $6 \mathrm{mg}$ and $100 \mu \mathrm{g} / \mathrm{kg}$ doses, we preferentially acquired the data for $6 \mathrm{mg}$. Authors of eligible articles were contacted by email if verification of their data was necessary. Data were collected by two different reviewers independently; any errors were checked by a third reviewer.

\section{Data items}

All the data from the included articles were checked to prevent the inclusion of duplicates. Study characteristics that were considered important were design, chemotherapy regimen, sample size, the time of blood collection, and drug interventions (dose). The clinical outcome features were extracted; primary outcomes included incidence or/and duration of grade $\geq 3$ neutropenia in cycle 1 . The secondary outcomes were the incidence of $\mathrm{FN}$, the time to absolute neutrophil count (ANC) recovery, and adverse events (AEs). Skeletal and/or muscle pain AEs were highlighted for analysis. 


\section{Quality assessment in individual studies}

The quality of the studies was assessed by two reviewers independently. For the RCTs, the Cochrane Collaboration tool was used to assess the risk of bias [18]. Any discrepancies in interpretation were resolved by consensus. The Cochrane Collaboration tool assesses six quality items: selection bias, performance bias, detection bias, attrition bias, reporting bias, and other bias. Based on the reviewers' judgments, every accepted article was evaluated as having a "low," "high," or "unclear" risk of bias.

\section{Data analysis}

Statistical analysis was performed using the Cochrane Collaboration's RevMan software, version 5.2 (Cochrane Collaboration, Oxford, UK). For dichotomous data, the comparative differences between the two groups are shown as risk ratios (RRs). For continuous data, the outcomes of the two groups were expressed as weighted mean differences (WMDs) with 95\% confidence intervals (CIs). Tests for heterogeneity were performed using Cochran's Q statistic and the $I^{2}$ test, with $P<0.05$ indicating significant heterogeneity. If the test for heterogeneity was statistically significant, then a random effects model was used; otherwise, the meta-analysis was performed using a fixed effects model.

\section{Results}

\section{Study selection and study characteristics}

A flowchart detailing the process of study identification and selection following the PRISMA statement is shown in Fig. 1. There were 404 records after duplicates were removed, and after screening the titles and abstracts for relevance, 26 articles were assessed further for eligibility. Among the 26 articles, 17 articles were excluded: 7 articles were only an abstract, 1 article was not in English, 4 articles were only related to long-acting G-CSF, 3 articles included patients with other types of cancer, and 2 articles were not RCTs. Thus, nine studies [19-27] were ultimately included in our present systematic review. Two of the identified papers were by the same author [19, 20]; therefore, we examined the data carefully. We found that the two papers included different samples and were from different publication years; therefore, the data of both papers could be used in the analysis and both papers were accepted. The characteristics of these nine studies are summarized in Table 1, while the outcomes of the nine studies are summarized in Table 2.

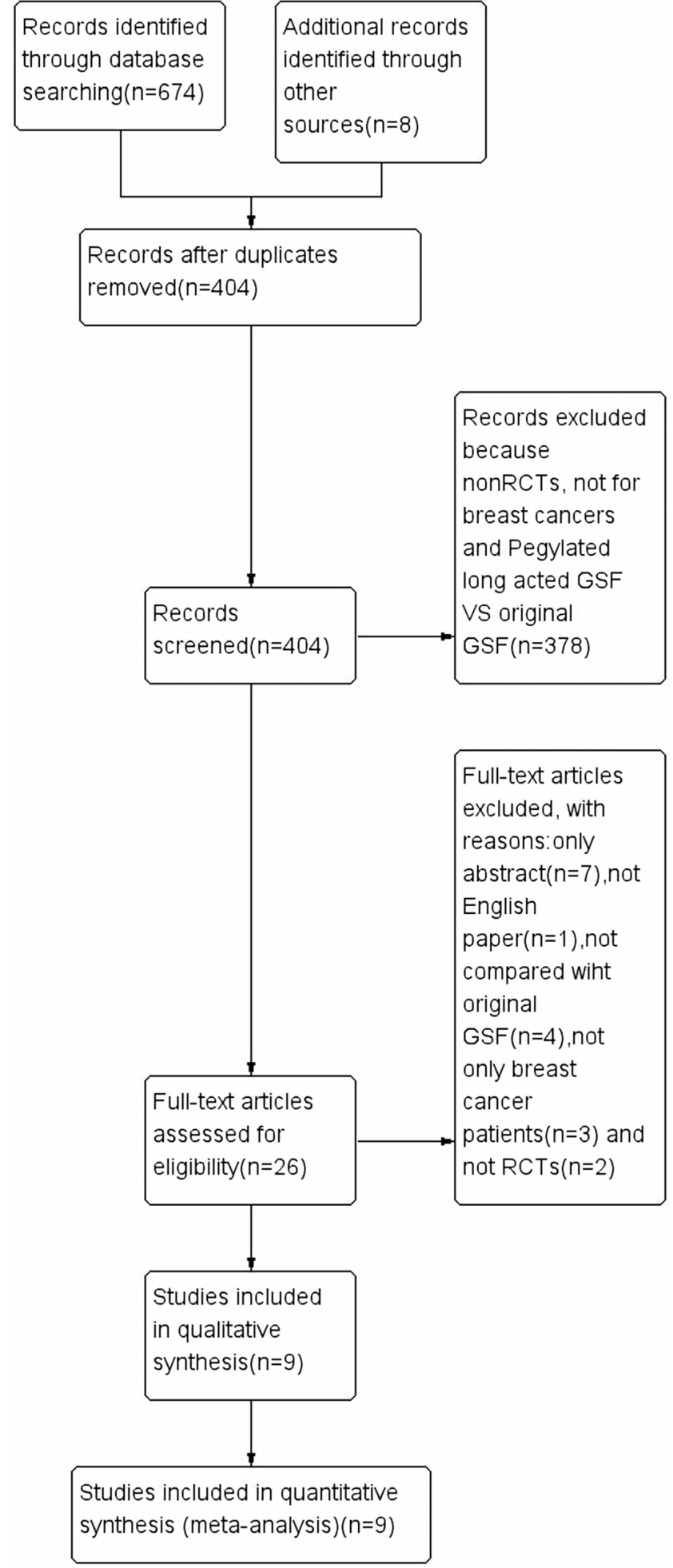

Fig. 1 Study flow diagram, inclusions, and exclusions following the PRISMA statement

\section{Risk of bias within the studies}

The risks of bias of all studies were assessed using the Cochrane Collaboration's tool. All the studies randomly 


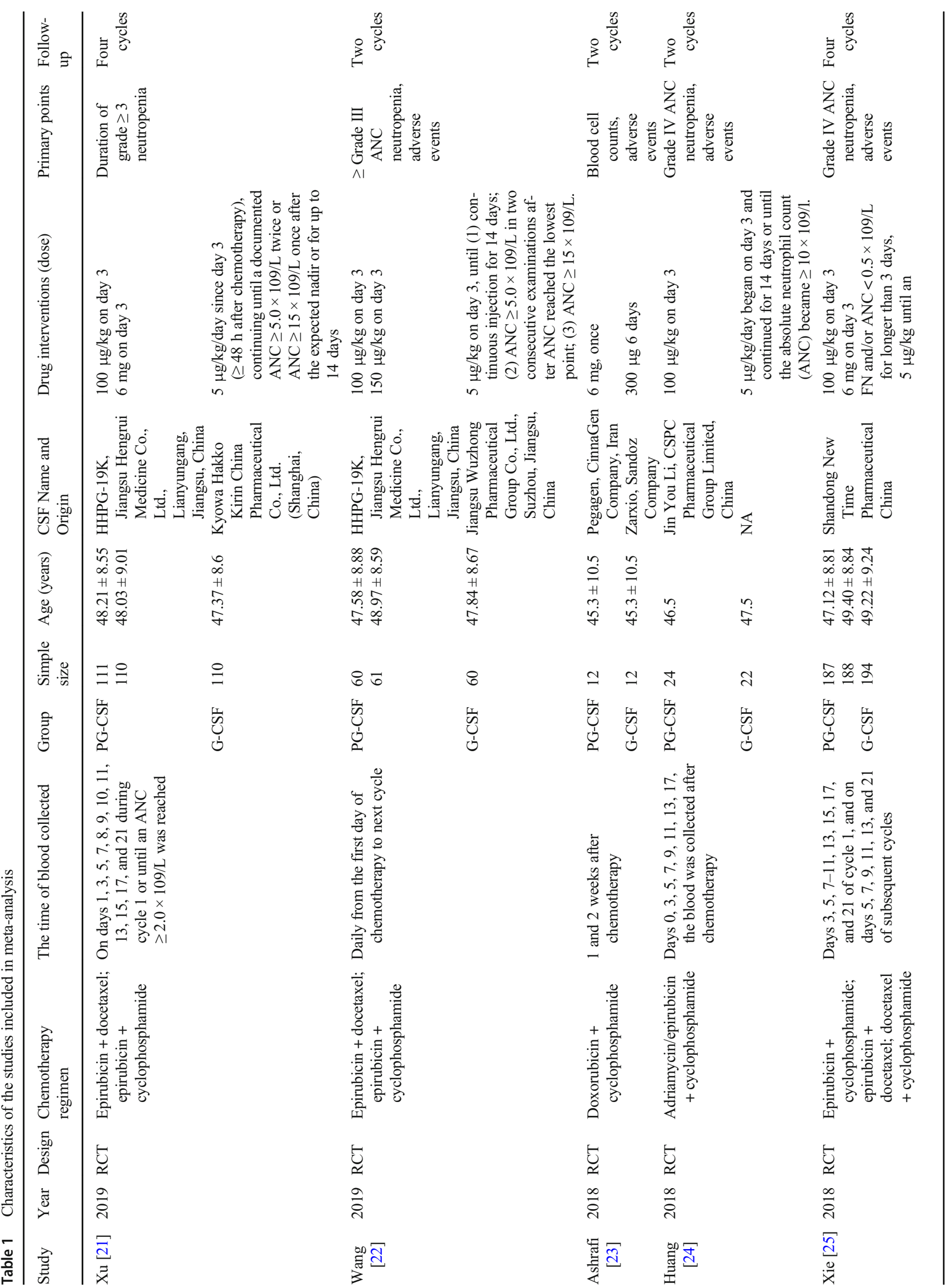




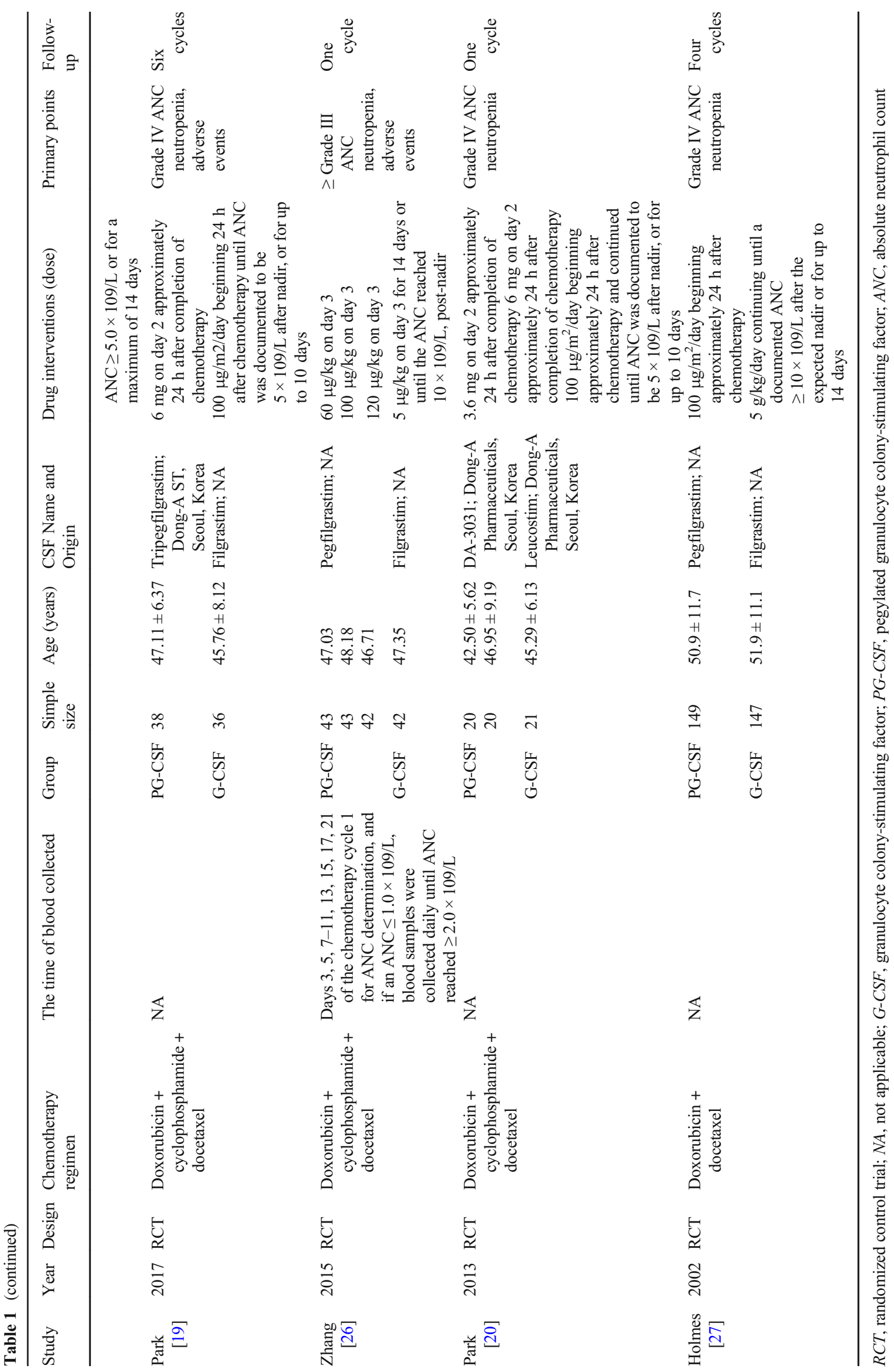




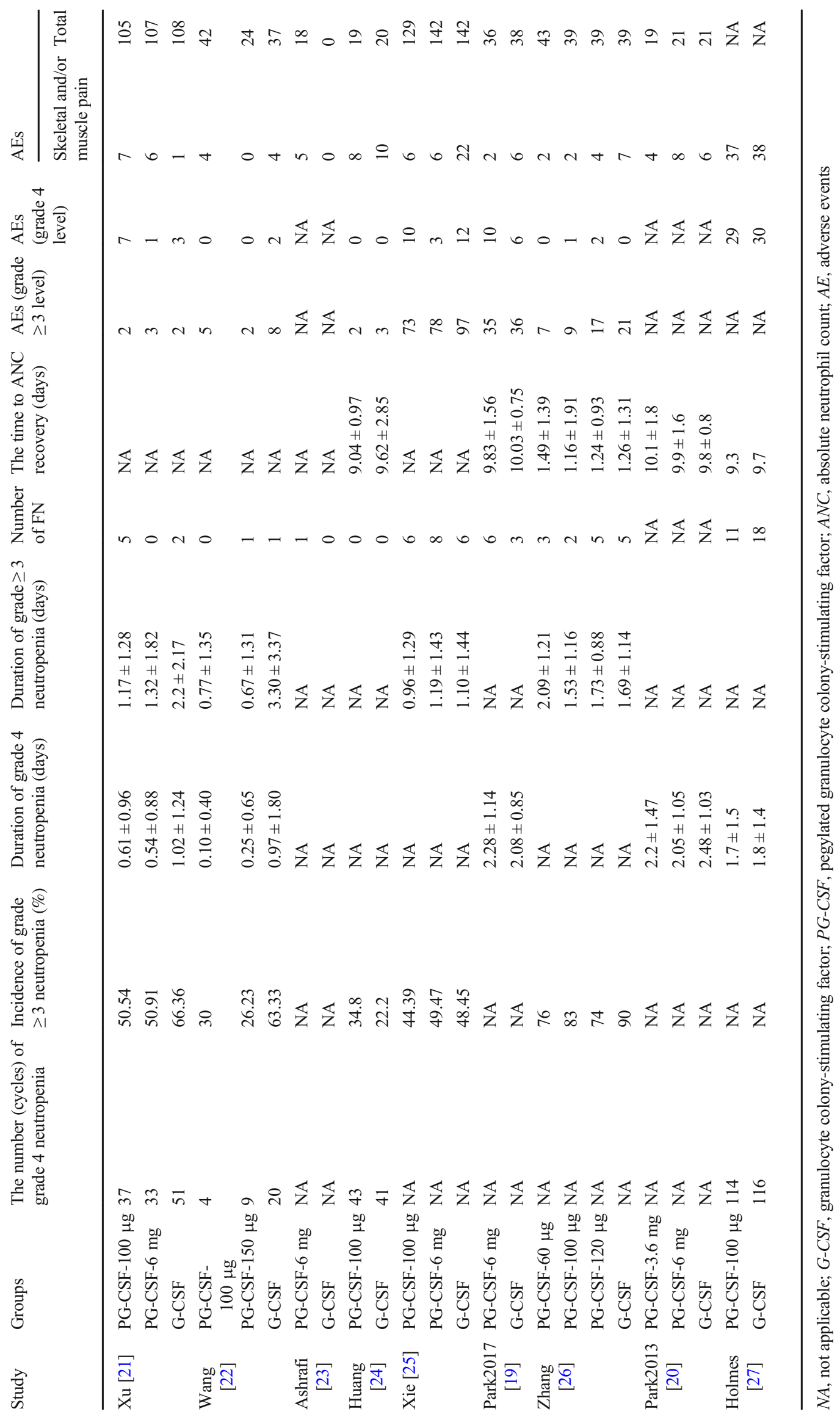


Fig. 2 Risk of bias graph: judgments about the risk of bias item presented in all included studies (a) and for each included study (b)
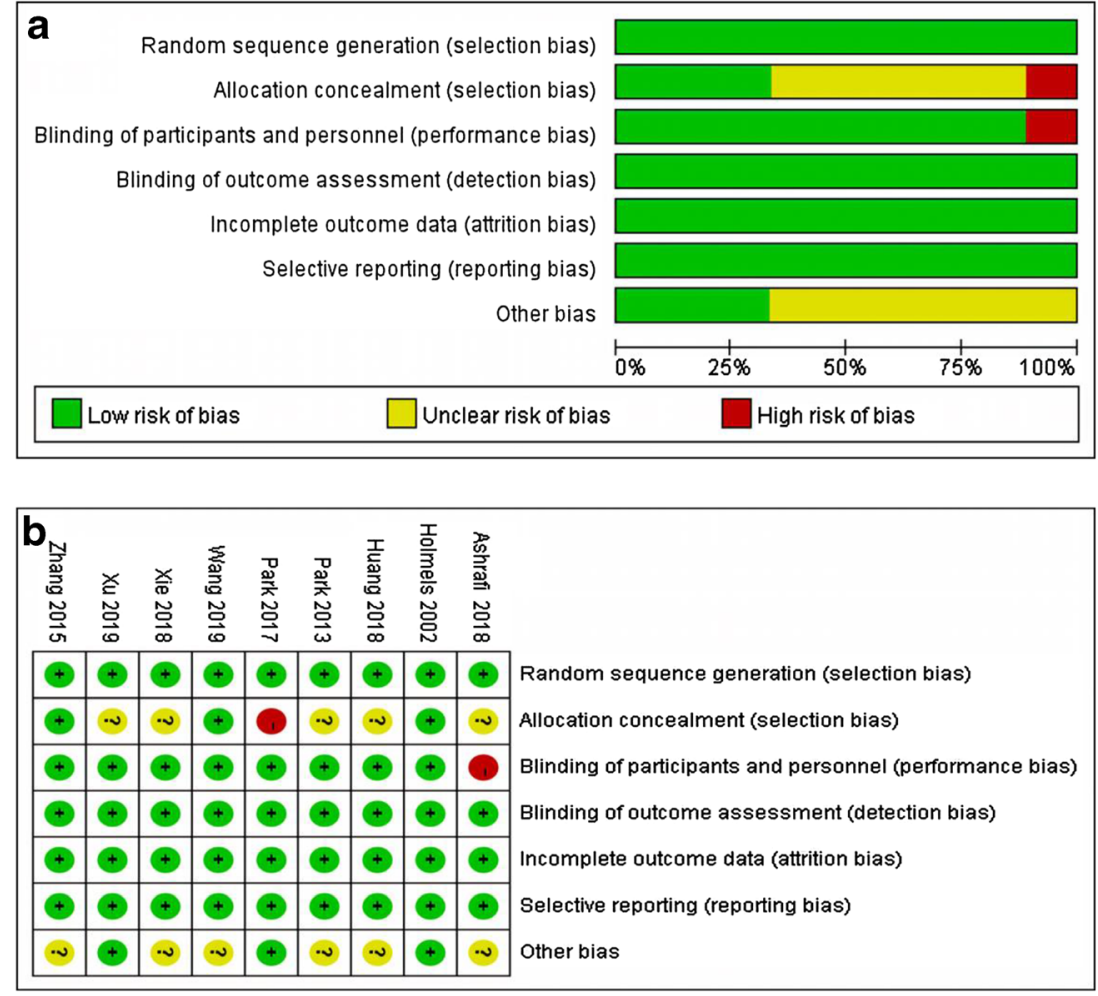

assigned the research objects and the outcomes were not affected by the blinded method. The included RCTs had a moderate risk of bias (Fig. 2). The publication bias was evaluated using a funnel plot [28].

\section{Results of individual studies and synthesis of the results}

\section{The incidence of grade $\geq 3$ neutropenia}

Only five studies $[21,22,24-26]$ provided information on the incidence of grade $\geq 3$ neutropenia. When we input all the data from these studies into the RevMan software, we found that the heterogeneity among the five studies was significant $(P=$ $0.003, I^{2}=75 \%$ ); therefore, sensitivity analysis of the five trials was performed. The analysis showed that the results were not substantially influenced by the heterogeneity. Therefore, we used the random effects model to analyze the final outcome, in which we did not observe a significant difference in the incidence of grade $\geq 3$ neutropenia between the two groups $(\mathrm{RR}=0.87 ; 95 \% \mathrm{CI} 0.69$ to $1.1 ; P=0.26)$ (Fig. 3a).

\section{The duration of grade $\geq 3$ neutropenia}

Four studies $[21,22,25,26]$ provided results for the duration of grade $\geq 3$ neutropenia. The heterogeneity among the studies was significant $\left(P<0.00001, I^{2}=94 \%\right)$; however, none of the studies in our analysis significantly influenced the heterogeneity, so we used the random effects model to analyze these data. The outcome showed that the duration of grade $\geq 3$ neutropenia between the two groups was not significantly different $(\mathrm{WMD}=-1.04,95 \% \mathrm{CI}-2.30$ to $-0.23, P=0.11)$ (Fig. 3b).

\section{The duration of grade 4 neutropenia}

Five studies [19-22, 27] reported the duration of grade 4 neutropenia. There was significant heterogeneity among the studies $\left(P=0.01, I^{2}=69 \%\right)$, necessitating the use of the random effects model. The results showed that the use of PEGylated G-CSF did not result in a significantly shorter duration of grade 4 neutropenia compared with that of G-CSF (WMD = $-0.32,95 \%$ CI 0.67 to $003, P=0.007)$. When we removed Wang's study [22] from the analysis, the heterogeneity decreased $\left(P=0.12, I^{2}=49 \%\right)$; however, the data from the Wang's data did not influence the final result $(P>0.05)$. Thus, although the included studies showed that the use of PEGylated G-CSF resulted a slight improvement in grade 4 neutropenia compared with that of G-CSF, the difference was not significant (Fig. 3c).

\section{The incidence of FN}

Only one study lacked data on this AE [20]; therefore, the remaining eight trials were used to compare the incidence of 
a

\begin{tabular}{|c|c|c|c|c|c|c|c|}
\hline \multirow[b]{2}{*}{ Study or Subgroup } & \multicolumn{2}{|c|}{ PEG-G-CSF group } & \multicolumn{2}{|c|}{ G-CSF group } & \multirow[b]{2}{*}{ Weight } & \multirow{2}{*}{$\begin{array}{c}\text { Risk Ratio } \\
\text { M-H. Random. } 95 \% \mathrm{Cl}\end{array}$} & \multirow{2}{*}{$\begin{array}{c}\text { Risk Ratio } \\
\text { M-H. Random. } 95 \% \mathrm{Cl}\end{array}$} \\
\hline & Events & Total & Events & Total & & & \\
\hline Huang 2018 & 16 & 24 & 10 & 22 & $11.7 \%$ & $1.47[0.86,2.51]$ & \\
\hline Wang 2019 & 18 & 60 & 38 & 60 & $15.0 \%$ & $0.47[0.31,0.73]$ & \\
\hline Xie 2018 & 93 & 188 & 94 & 194 & $24.3 \%$ & $1.02[0.83,1.25]$ & \\
\hline Xu 2019 & 56 & 110 & 73 & 110 & $23.3 \%$ & $0.77[0.61,0.96]$ & \\
\hline Zhang 2015 & 36 & 43 & 38 & 43 & $25.7 \%$ & $0.95[0.80,1.12]$ & \\
\hline Total $(95 \% \mathrm{Cl})$ & & 425 & & 429 & $100.0 \%$ & $0.87[0.69,1.10]$ & \\
\hline Total events & 219 & & 253 & & & & \\
\hline $\begin{array}{l}\text { Heterogeneity: } \mathrm{Tau}^{2}= \\
\text { Test for overall effect }\end{array}$ & $\begin{array}{l}.05 ; \mathrm{Chi}^{2}= \\
=114(\mathrm{P}=\end{array}$ & (7, df $=$ & $4(P=0 . C$ & 4); $; 1^{2}=$ & $74 \%$ & & 0.512 \\
\hline
\end{tabular}

b

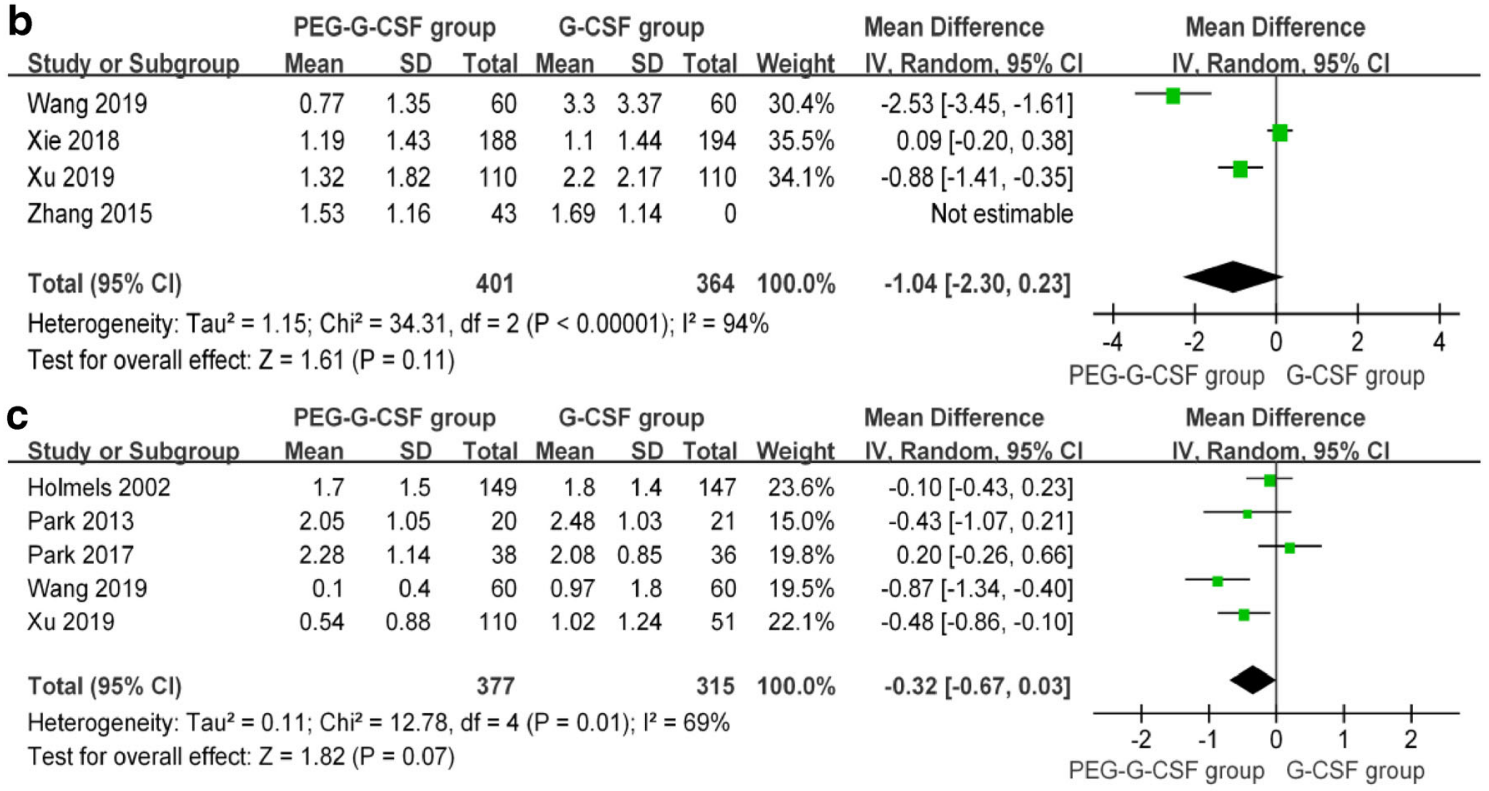

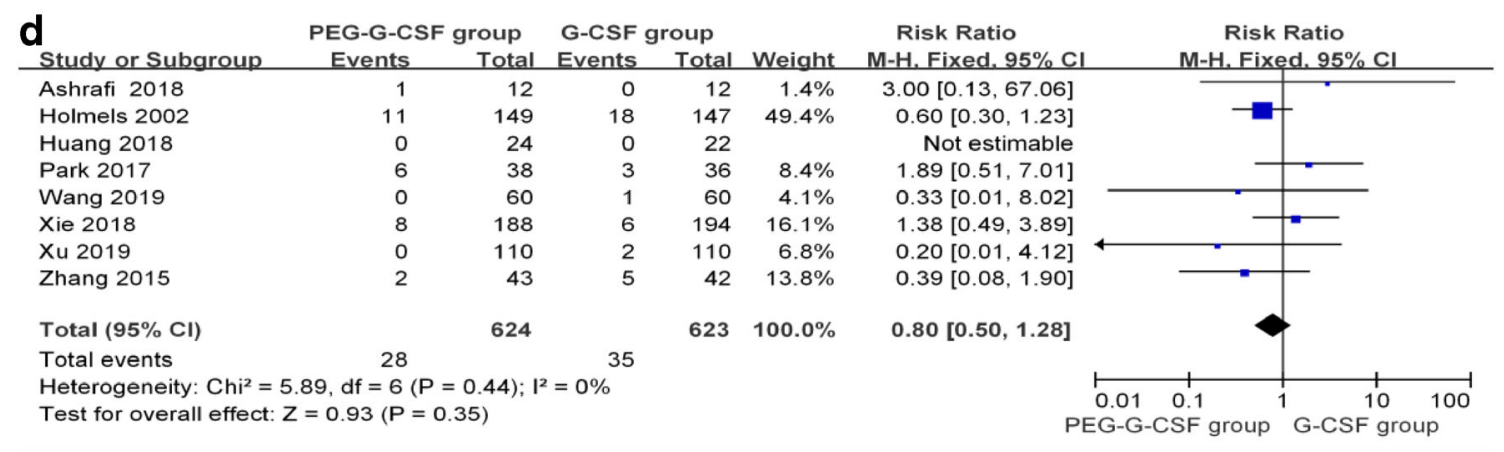

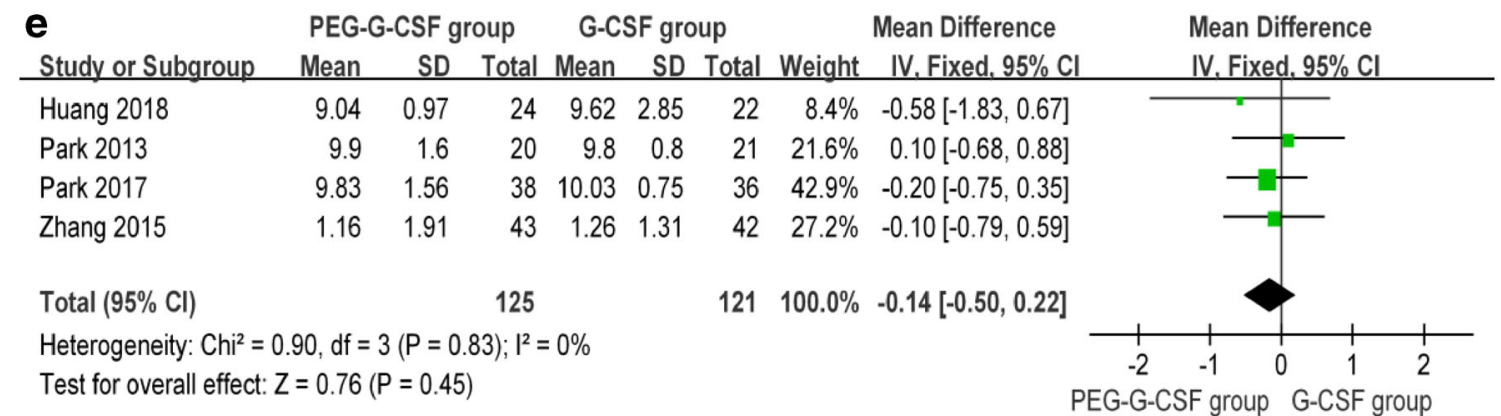

Fig. 3 Forest plot comparing the results of effectiveness between the two groups. a Incidence of grade $\geq 3$ neutropenia; $\mathbf{b}$ duration of grade $\geq 3$ neutropenia; $\mathbf{c}$ duration of grade 4 neutropenia; $\mathbf{d}$ incidence of febrile neutropenia (FN); $\mathbf{e}$ the time to ANC recovery 


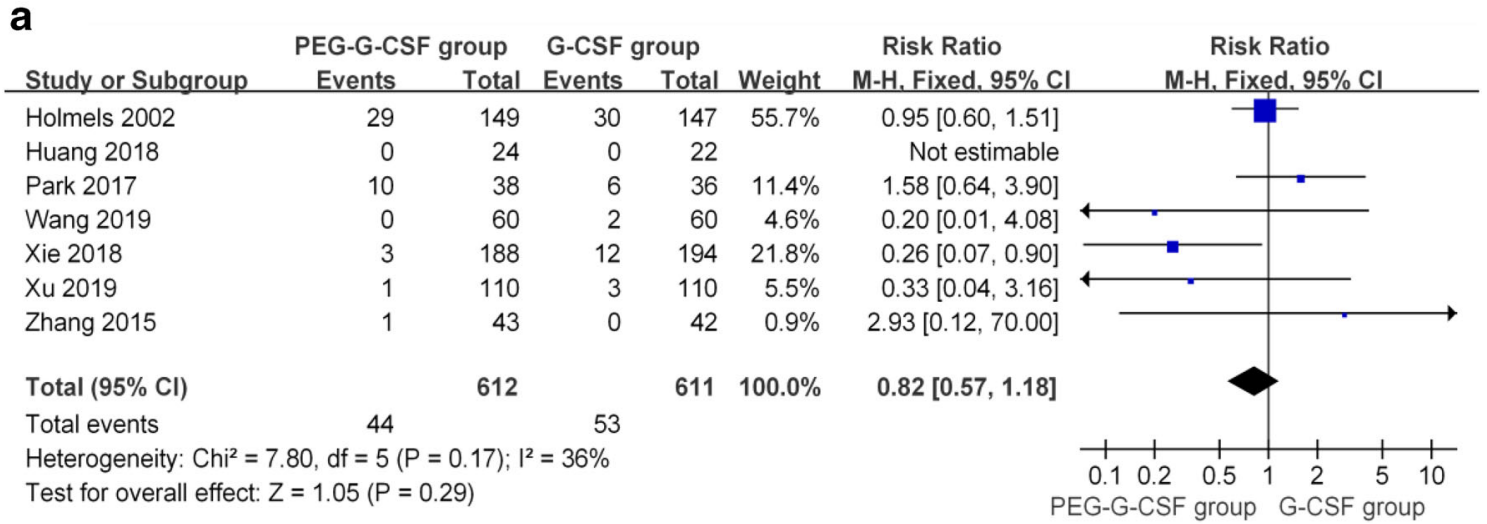

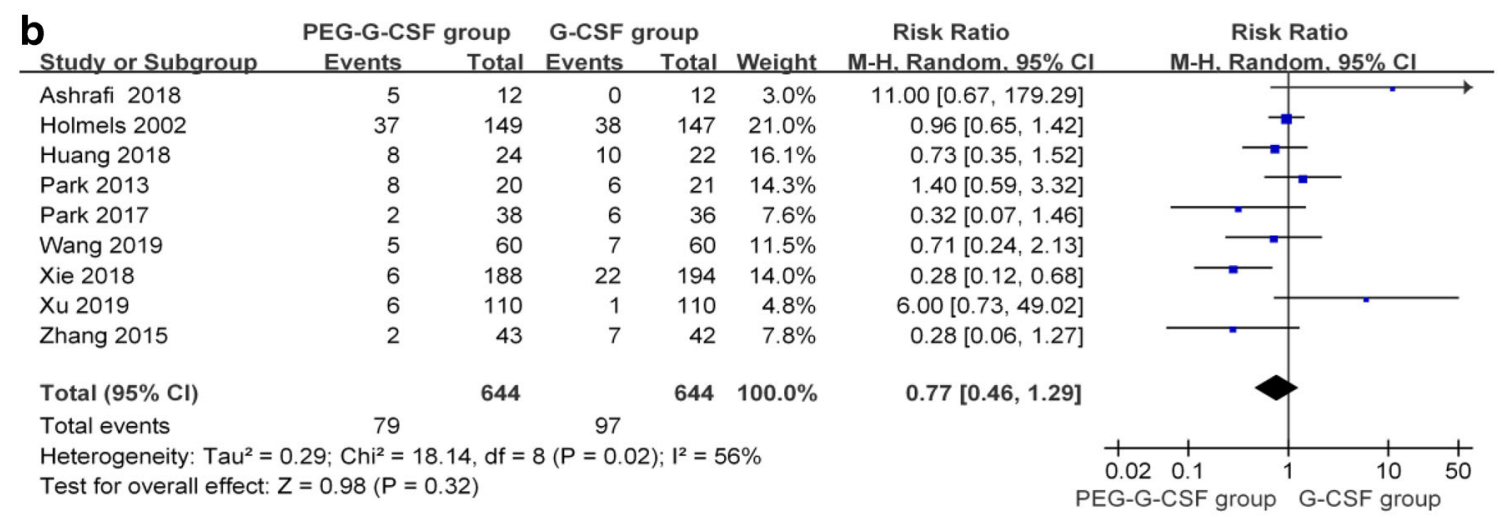

Fig. 4 Forest plot comparing the results of safety between the two groups. a grade 4 adverse (AEs); $\mathbf{b}$ incidence of skeletal and/or muscle pain

FN between the two groups. There was no significant heterogeneity among these studies $\left(P=0.44, I^{2}=0 \%\right)$; therefore, we used the fixed effects model to analyze the results. There was no significant difference between the two groups $(\mathrm{RR}=0.80$; 95\% CI 0.50 to $1.28 ; P=0.35$ ) (Fig. 3D); thus, PEGylated GCSF had no obvious advantage in improving the FN of CIN in patients with breast cancer.

\section{The time to ANC recovery}

Five studies [19, 20, 24, 26, 27] reported information concerning the time to ANC recovery. However, the study by Holmes et al. [27] only described the median time of ANC recovery; therefore, we excluded that article from this part of the meta-analysis. The pooled analysis of the results showed no significant heterogeneity $\left(P=0.83, I^{2}=0 \%\right)$. Using a fixed effects model, the pooled results showed that there was no significant difference between two groups for the time to $\mathrm{ANC}$ recovery $(\mathrm{WMD}=-0.14,95 \% \mathrm{CI}-0.50$ to $0.22, P=0.45)$ (Fig. 3e).

\section{The grade 4 AEs of the two groups}

Seven studies [19, 21, 22, 24-27] reported the specific numbers of grade 4 AEs. The study by Huang et al. [24] reported no grade 4 AEs; therefore, that study was not included in the analysis. Using a fixed effects model, the pooled results showed that the grade 4 AEs of the two groups were not significantly different $(\mathrm{RR}=0.82 ; 95 \%$ CI 0.57 to $1.18 ; P=$ $0.29)$, without significant heterogeneity $\left(P=0.17, I^{2}=36 \%\right)$ (Fig. 4a).

\section{Skeletal and/or muscle pain}

All nine studies [19-27] provided information about this AE. The pooled analysis showed significant heterogeneity among the studies $\left(P=0.02, I^{2}=56 \%\right)$; therefore, a random effects model was used for the analysis. The results indicated no significant difference between the two groups $(R R=0.77$;

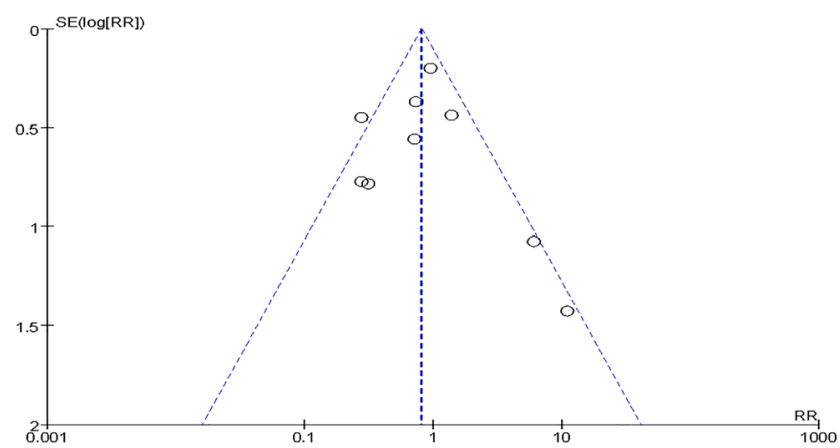

Fig. 5 Funnel plot illustrating the meta-analysis of skeletal and/or muscle pain 
95\% CI 0.46 to $1.29 ; P=0.32$ ) (Fig. 4B). Meanwhile, we also performed a sensitivity analysis of these studies and found that when we removed Xie's study [25], the heterogeneity decreased $\left(P=0.10, I^{2}=42 \%\right)$; however, the pooled results still showed that there was no difference between the groups in terms of skeletal and/or muscle pain using a fixed effects model (RR $=0.96 ; 95 \%$ CI 0.72 to $1.27 ; P=0.76$ ). Thus, the use of PEGylated G-CSF did not increase the incidence of skeletal and/or muscle pain significantly compared with that of G-CSF.

\section{Publication bias}

All nine studies [19-27] provided information about skeletal and/or muscle pain; therefore, we created a funnel plot based on this result, which showed that only one study was outside of the $95 \% \mathrm{CI}$, while the rest of the studies lay inside, showing a low distribution around the verticals and indicating an acceptable level of publication bias for these studies (Fig. 5).

\section{Discussion}

CIN is one of the most common side effects of chemotherapy, which usually leads to chemotherapy dose reduction and/or treatment delay, which might compromise the effectiveness of chemotherapy [29]. The clinical use of G-CSF has greatly improved the safety of chemotherapy. The prophylactic use of G-CSF in chemotherapy significantly reduced the incidence of FN from 24 to $7-16 \%$ [19, 30, 31]. Breast cancer has different molecular subtypes, and chemosensitivity might be associated with dose intensity: The higher the relative dose intensity, the higher the response rate of patients with breast cancer, especially those with luminal subtypes [32,33]. Dosedense chemotherapy regimens in breast cancer induce a higher rate of CIN, necessitating the daily injection of G-CSF [12, 34]. The emergence of PEGylated G-CSF has greatly reduced the number of injections required, making it more convenient for the patients, especially those who live far away from the hospital. Both types of G-CSF are effective, and Cornes et al. [17] also performed a systematic review of short- versus longacting G-CSF, but they showed that the two kinds of G-CSF had no difference of effectiveness included different types of cancer. Therefore, because the safety and efficacy of PEGylated G-CSF compared with that of G-CSF for CIN of breast cancer have not been conclusively determined, we conducted an up-to-date systematic review based on RCTs to provide the current best evidence on this topic.

Lambertini et al. [21,35] suggested that compared with GCSF, PEGylated G-CSF showed superior efficacy, and for high FN chemotherapy regimens, such as AT (anthracyclines-taxane), resulted in a shorter duration of
CIN. However, the results of the present study revealed no significant difference in the efficacy indicators between the two drugs $(P>0.05)$. We did not find a significant difference for the incidence/duration of grade $\geq 3$ neutropenia between the two groups $(P>0.05)$, and although in most of the studies the PEGylated G-CSF slightly improved grade 4 neutropenia, the difference was not significant for the duration of grade 4 neutropenia $(P=0.007)$. All the included studies were RCTs, in which the short-acting G-CSF was used according to recommended guidelines, requiring an average of more than six injections to support ANC recovery to $>2.0 \times 10^{9} / \mathrm{L}$ or up to 10 days. Our study also showed that when the short-acting GCSF was used according to the guidelines, the use of PEGylated G-CSF did not result in a shorter time to ANC recovery $(P=0.45)$. However, in the articles [36-38] that showed evidence for greater efficacy of PEGylated G-CSF, this may have been the result of the underdosing of shortacting G-CSF in the non-RCTs, which was possibly closer to the real-world situations [17]. In the real world, though more regular visits to the hospital to receive a daily injection may be a source of better psychosocial support, which also would increase the pain of hypodermic injection and the burden to patients, resulting in missed appointments and patients not receiving a sufficient dose of G-CSF [17, 39]. And, in clinical practice, some physicians had shown that using PEGylated G-CSF could result in significant time savings and the pain decrease for patients by reducing the number of injections, which could improve the quality of life (QOL) and treatment compliance for patients [40-42].

FN is considered a severe complication, which could be life-threatening and is associated with a high risk of mortality. Some studies [27, 43-45] showed that the incidence of FN might be significantly different in cycles 2 to 4 and that PEGylated G-CSF could perform better than G-CSF in support of patients' recovery from FN. However, our pooled results from eight studies [19, 21-27] showed that PEGylated G-CSF had no obvious advantage over G-CSF in improving $\mathrm{FN}$ of CIN in patients with breast cancer $(P=0.35)$. This was possible because we only included the data of the first cycle and all the patients in the control groups received sufficient doses of short-acting G-CSF. Meanwhile, we only included patients with breast cancer, who perhaps had a relatively better prognosis compared with that of other tumors.

AEs occurred in most of the included patients; however, the majority of them were related to chemotherapy and were not serious. Ashrafi reported higher numbers of AEs induced by PEGylated G-CSF [23]; however, seven studies [19, 21, 22, 24-27] reported the specific numbers of grade 4 AEs and the final result showed no significant difference between the two groups for grade 4 AEs $(P=0.29)$, suggesting that PEGylated G-CSF is just as safe as G-CSF. None of the articles reported unexpected AEs related to either drug, such as spleen rupture. The most common adverse reaction induced 
by PEGylated G-CSF is skeletal and/or muscle pain [23, 46]. However, the results of the present study showed that PEGylated G-CSF did not significantly increase the incidence of skeletal and/or muscle pain $(P=0.32)$, and the articles that did report this $\mathrm{AE}$ noted only mild to moderate, rather than unbearable, pain. Xu et al. [21] also found that a fixed dosage of PEGylated G-CSF did not influence the effectiveness or increase the related AEs in over- or underweight patients. Meanwhile, Shi et al. [47] found that PEGylated G-CSF did not increase the AEs related to different chemotherapy. Thus, we concluded that PEGylated G-CSF was as safe as G-CSF to treat CIN in patients with breast cancer but did not show an obvious superiority.

Several limitations were associated with the included randomized studies. First, the main limitation was that the included studies were all RCTS with a relatively small size and lacked real-world data, which might have decreased the reliability and could cause bias. Second, different studies used different outcome measurements with different blood collection times, and some FN events might not have been captured accurately because some studies had not made a distinction between FN and FN-related endpoints. Third, PEGylated GCSF was delivered at two recommended doses and as different types (original or biosimilar), and the included studies did not use the same dose and type of PEGylated G-CSF, although the studies had confirmed that the two doses and types of PEGylated G-CSF were similarly effective [14, 19, 21, 22, $25,48]$, which could have led to bias.

In conclusion, when short-acting G-CSF is used at a sufficient dose according to the recommended guidelines, PEGylated G-CSF did not show an obvious advantage over G-CSF in the chemotherapy of patients with breast cancer. However, PEGylated G-CSF facilitates out-patient chemotherapy, improves the patients' QOL by decreasing the numbers of injections, and reduces the number of hospital visits, especially in the time of COVID-19 pandemic, which could decrease the incidence of COVID-19 infection. In addition, PEGylated G-CSF did not increase the incidence of AEs. Thus, for the chemotherapy of breast cancer, PEGylated GCSF has no obvious superiority in terms of effectiveness and safety over G-CSF, whereas, in actual clinical practice, it is more convenient.

Author's contributions LI X. and Zheng H. performed the information retrieval, screened the potential subjects, and extracted and integrated the data independently at the same time; Yu M.C. and Wang W. checked the data and designed the review; Wu X.H. drafted the initial manuscript; Yang Dong-mei and $\mathrm{Xu}$ J. reviewed the final manuscript; all the authors approved the final manuscript.

\section{Compliance with ethical standards}

Conflict of interest The authors declare that they have no conflict of interest.

\section{References}

1. Bray F, Ferlay J, Soerjomataram I, Siegel RL, Torre LA, Jemal A (2018) Global cancer statistics 2018: GLOBOCAN estimates of incidence and mortality worldwide for 36 cancers in 185 countries. CA Cancer J Clin 68:394-424

2. Bonadonna G, Valagussa P, Moliterni A, Zambetti M, Brambilla C (1995) Adjuvant cyclophosphamide, methotrexate, and fluorouracil in node-positive breast cancer: the results of 20 years of follow-up. N Engl J Med 332:901-906

3. Gray R, Bradley R, Braybrooke J, Davies C, Pan H, Peto R, Bliss J, Cameron D, Mackey J, Del Mastro L, Swain S, Untch M, Bergh J, Pritchard K, Norton L (2018) Abstract GS1-01: increasing the dose density of adjuvant chemotherapy by shortening intervals between courses or by sequential drug administration significantly reduces both disease recurrence and breast cancer mortality: an EBCTCG meta-analysis of 21,000 women in 16 randomised trials. Cancer Res 78:GS1-G01

4. Lalami Y, Klastersky J (2017) Impact of chemotherapy-induced neutropenia $(\mathrm{CIN})$ and febrile neutropenia $(\mathrm{FN})$ on cancer treatment outcomes: an overview about well-established and recently emerging clinical data. Crit Rev Oncol Hematol 120:163-179

5. Kim HS, Lee SY, Kim JW, Choi YJ, Park IH, Lee KS, Seo JH, Shin SW, Kim YH, Kim JS, Park KH (2016) Incidence and predictors of febrile neutropenia among early-stage breast cancer patients receiving anthracycline-based chemotherapy in Korea. Oncology 91:274-282

6. Marsh JC, Ganser A, Stadler M (2007) Hematopoietic growth factors in the treatment of acquired bone marrow failure states. Semin Hematol 44:138-147

7. Welte K, Gabrilove J, Bronchud MH, Platzer E, Morstyn G (1996) Filgrastim (r-metHuG-CSF): the first 10 years. BLOOD 88:1907-1929

8. Aapro MS, Bohlius J, Cameron DA, Dal Lago L, Donnelly JP, Kearney N, Lyman GH, Pettengell R, Tjan-Heijnen VC, Walewski J, Weber DC, Zielinski C (2011) 2010 update of EORTC guidelines for the use of granulocyte-colony stimulating factor to reduce the incidence of chemotherapy-induced febrile neutropenia in adult patients with lymphoproliferative disorders and solid tumours. Eur J Cancer 47:8-32

9. Crawford J, Caserta C, Roila F (2010) Hematopoietic growth factors: ESMO Clinical Practice Guidelines for the applications. ANN ONCOL 21 Suppl 5, v248-51

10. Fernandes R, Mazzarello S, Stober C, Ibrahim M, Dudani S, Perdrizet K, Majeed H, Vandermeer L, Shorr R, Hutton B, Fergusson D, Gyawali B, Clemons M (2018) Primary febrile neutropenia prophylaxis for patients who receive FEC-D chemotherapy for breast cancer: a systematic review. J Glob Oncol 4:1-8

11. Tan H, Tomic K, Hurley D, Daniel G, Barron R, Malin J (2011) Comparative effectiveness of colony-stimulating factors for febrile neutropenia: a retrospective study. Curr Med Res Opin 27:79-86

12. Bond TC, Szabo E, Gabriel S, Klastersky J, Tomey O, Mueller U, Schwartzberg L, Tang B (2018) Meta-analysis and indirect treatment comparison of lipegfilgrastim with pegfilgrastim and filgrastim for the reduction of chemotherapy-induced neutropeniarelated events. J Oncol Pharm Pract 24:412-423

13. Kuan JW, Su AT, Leong CF (2017) Pegylated granulocyte-colony stimulating factor versus non-pegylated granulocyte-colony stimulating factor for peripheral blood stem cell mobilization: a systematic review and meta-analysis. J Clin Apher 32:517-542

14. Botteri E, Krendyukov A, Curigliano G (2018) Comparing granulocyte colony-stimulating factor filgrastim and pegfilgrastim to its biosimilars in terms of efficacy and safety: a meta-analysis of randomised clinical trials in breast cancer patients. Eur J Cancer 89:49-55 
15. Hendler D, Rizel S, Yerushalmi R, Neiman V, Bonilla L, Braunstein R, Sulkes A, Stemmer SM (2011) Different schedules of granulocyte growth factor support for patients with breast cancer receiving adjuvant dose-dense chemotherapy: a prospective nonrandomized study. Am J Clin Oncol 34:619-624

16. Schwartzberg LS, Yang Z, Peguero JA, Agajanian R, Bharadwaj JS, Restrepo A, Hlalah O, Mehmi I, Bhat G, Cobb PW (2018) Safety and efficacy of eflapegrastim in reducing severe neutropenia in patients treated with myelosuppressive chemotherapy in a phase 3 randomized controlled trial compared to pegfilgrastim (ADVANCE trial). J Clin Oncol:36

17. Cornes P, Gascon P, Chan S, Hameed K, Mitchell CR, Field P, Latymer M, Arantes LH (2018) Systematic review and metaanalysis of short- versus long-acting granulocyte colonystimulating factors for reduction of chemotherapy-induced febrile neutropenia. Adv Ther 35:1816-1829

18. Higgins JPT, Altman DG, Gøtzsche PC, Jüni P, Moher D, Oxman AD, Savović J, Schulz KF, Weeks L, Sterne JAC (2011) The Cochrane Collaboration's tool for assessing risk of bias in randomised trials. BMJ 343:d5928

19. Park KH, Lee S, Park JH, Kang SY, Kim HY, Park IH, Park YH, Im YH, Lee HJ, Park S, Lee SI, Jung KH, Kim YS, Seo JH (2017) A randomized, multi-center, open-label, phase III study of onceper-cycle DA-3031, a pegylated G-CSF, in comparison with daily filgrastim in patients receiving TAC chemotherapy for breast cancer. Support Care Cancer 25:505-511

20. Park KH, Sohn JH, Lee S, Park JH, Kang SY, Kim HY, Park IH, Park YH, Im YH, Lee HJ, Hong DS, Park S, Shin SH, Kwon HC, Seo JH (2013) A randomized, multi-center, open-label, phase II study of once-per-cycle DA-3031, a biosimilar pegylated G-CSF, compared with daily filgrastim in patients receiving TAC chemotherapy for early-stage breast cancer. Investig New Drugs 31: 1300-1306

21. Xu F, Zhang Y, Miao Z, Zeng X, Wu B, Cai L, Liu J, Wang S, Hu X, Zheng W, Chen Z, Yang Q, Jiang Z (2019) Efficacy and safety of mecapegfilgrastim for prophylaxis of chemotherapy-induced neutropenia in patients with breast cancer: a randomized, multicenter, active-controlled phase III trial. Ann Transl Med 7:482

22. Wang T, Wu B, Hu X, Liu J, Zhang T, Li F, Sun B, Cai L, Li X, Chen Z, Yang Q, Jiang Z (2019) A randomized multicenter phase II trial of mecapegfilgrastim single administration versus granulocyte colony-stimulating growth factor on treating chemotherapyinduced neutropenia in breast cancer patients. Ann Transl Med:7

23. Ashrafi F, Salmasi M (2018) Comparison of the effects of pegylated granulocyte-colony stimulating factor and granulocyte-colony stimulating factor on cytopenia induced by dose-dense chemotherapy in breast cancer patients. J Res Med Sci 23:73

24. Huang W, Liu J, Zeng Y, Wu F, Li N, Chen K, Hong Y, Wang L, Zhen H, Lin L (2018) Randomized controlled clinical trial of polyethylene glycol recombinant human granulocyte colonystimulating factor in the treatment of neutropenia after chemotherapy for breast cancer. Cancer Chemother Pharmacol 82:607-613

25. Xie J, Cao J, Wang JF, Zhang BH, Zeng XH, Zheng H, Zhang Y, Cai L, Wu YD, Yao Q, Zhao XC, Mao WD, Jiang AM, Chen SS, Yang SE, Wang SS, Wang JH, Pan YY, Ren BY, Chen YJ, Ouyang LZ, Lei KJ, Gao JH, Huang WH, Huang Z, Shou T, He YL, Cheng J, Sun Y, Li WM, Cui SD, Wang X, Rao ZG, Ma H, Liu W, Wu XY, Shen WX, Cao FL, Xiao ZM, Wu B, Tian SY, Meng D, Shen P, Wang BY, Wang Z, Zhang J, Wang L, Hu XC (2018) Advantages with prophylactic PEG-rhG-CSF versus rhG-CSF in breast cancer patients receiving multiple cycles of myelosuppressive chemotherapy: an open-label, randomized, multicenter phase III study. Breast Cancer Res Treat 168:389-399

26. Zhang W, Jiang Z, Wang L, Li C, Xia J (2015) An open-label, randomized, multicenter dose-finding study of once-per-cycle pegfilgrastim versus daily filgrastim in Chinese breast cancer patients receiving TAC chemotherapy. Med Oncol 32:147

27. Holmes FA, O'Shaughnessy JA, Vukelja S, Jones SE, Shogan J, Savin M, Glaspy J, Moore M, Meza L, Wiznitzer I, Neumann TA, Hill LR, Liang BC (2002) Blinded, randomized, multicenter study to evaluate single administration pegfilgrastim once per cycle versus daily filgrastim as an adjunct to chemotherapy in patients with high-risk stage II or stage III/IV breast cancer. J Clin Oncol 20: 727-731

28. Ioannidis JP, Trikalinos TA (2007) The appropriateness of asymmetry tests for publication bias in meta-analyses: a large survey. CMAJ 176:1091-1096

29. Quartino AL, Karlsson MO, Lindman H, Friberg LE (2014) Characterization of endogenous G-CSF and the inverse correlation to chemotherapy-induced neutropenia in patients with breast cancer using population modeling. Pharm Res 31:3390-3403

30. Martín M, Lluch A, Seguí MA, Ruiz A, Ramos M, Adrover E, Rodríguez-Lescure A, Grosse R, Calvo L, Fernandez-Chacón C, Roset M, Antón A, Isla D, del Prado P, Iglesias L, Zaluski J, Arcusa A, López-Vega JM, Muñoz M, Mel JR (2006) Toxicity and health-related quality of life in breast cancer patients receiving adjuvant docetaxel, doxorubicin, cyclophosphamide (TAC) or 5fluorouracil, doxorubicin and cyclophosphamide (FAC): impact of adding primary prophylactic granulocyte-colony stimulating factor to the TAC regimen. Ann Oncol 17:1205-1212

31. Aapro M, Schwenkglenks M, Lyman GH, Lopez Pousa A, Lawrinson S, Skacel T, Bacon P, von Minckwitz G (2010) Pegfilgrastim primary prophylaxis vs. current practice neutropenia management in elderly breast cancer patients receiving chemotherapy. Crit Rev Oncol Hematol 74:203-210

32. Yuan JQ, Wang SM, Tang LL, Mao J, Wu YH, Hai J, Luo SY, Ou HY, Guo L, Liao LQ, Huang J, Li Y, Xiao Z, Zhang KJ, Luo N, Chen FY (2015) Relative dose intensity and therapy efficacy in different breast cancer molecular subtypes: a retrospective study of early stage breast cancer patients treated with neoadjuvant chemotherapy. Breast Cancer Res Treat 151:405-413

33. Del Mastro L, De Placido S, Bruzzi P, De Laurentiis M, Boni C, Cavazzini G, Durando A, Turletti A, Nisticò C, Valle E (18631872) Fluorouracil and dose-dense chemotherapy in adjuvant treatment of patients with early-stage breast cancer: an open-label, $2 ? \times ? 2$ factorial, randomised phase 3 trial. LANCET 385

34. Budisavljevic A (2018) Dose dense chemotherapy, is there a catch? Libr Oncol 45:15

35. Lambertini M, Ferreira AR, Del ML, Danesi R, Pronzato P (2015) Pegfilgrastim for the prevention of chemotherapy-induced febrile neutropenia in patients with solid tumors. Expert Opin Biol Ther 15:1799-1817

36. Wetten S, Li X, Haas J, Worth G, Jacob C, Braun S, Tzivelekis S Comparative effectiveness of granulocyte colony-stimulating factors (G-Csf) for reducing incidence of febrile neutropenia (Fn) related hospitalization: a retrospective cohort study using German claims data. Value in Health the Journal of the International Society for Pharmacoeconomics \& Outcomes Research 18, A434

37. Morrison VA, Mitchell W, Dawn H, Campos LT, Beiying D, Jennifer M Observational study of the prevalence of febrile neutropenia in patients who received filgrastim or pegfilgrastim associated with 3-4 week chemotherapy regimens in community oncology practices. J Manag Care Pharm 13:337-348

38. Naeim A, Henk HJ, Becker L, Chia V, Badre S, Li X, Deeter R (2013) Pegfilgrastim prophylaxis is associated with a lower risk of hospitalization of cancer patients than filgrastim prophylaxis: a retrospective United States claims analysis of granulocyte colonystimulating factors (G-CSF). BMC Cancer 13:11

39. Mitchell S, Li X, Woods M, Garcia J, Hebard-Massey K, Barron R, Samuel M (2016) Comparative effectiveness of granulocyte colony-stimulating factors to prevent febrile neutropenia and related 
complications in cancer patients in clinical practice: a systematic review. J Oncol Pharm Pract 22:702-716

40. Montella L, Addeo R, Guarrasi R, Cennamo G, Faiola V, Capasso E, Caraglia M, Del PS (2010) Once-per-cycle pegfilgrastim in breast cancer patients treated with docetaxel/epidoxorubicin/cyclophosphamide. Eur J Cancer Care (Engl) 19:200-204

41. Morishita M, Leonard RC (2008) Pegfilgrastim; a neutrophil mediated granulocyte colony stimulating factor-expanding uses in cancer chemotherapy. Expert Opin Biol Ther 8:993-1001

42. Beveridge RA, Rifkin RM, Moleski RJ, Milkovich G, Reitan JF, Paivanas TA, Jacobs RJ (2003) Impact of long-acting growth factors on practice dynamics and patient satisfaction. Pharmacotherapy 23:101S-109S

43. Jiang Z, Xu FR, Fan J, Li BJ, Gao JN, Hu JW, Wang XJ, Zhang YQ, Wang JH, Li F, Liu Q, Liu YH, Wang S, Wang YS, Ouyang QC, Hu B, Sun GP, Zhang Y, Zang AM, Fan PZ, Wu CP, Liu J, Zhang HW, Wang W, Hu XC, Tang LL, Zhang J, Bao YY, Geng CZ, Sun Q, Zhang F, Yin YM, Jiang HC, An YH (2018) A multicenter, randomized, controlled, phase IV clinical study of PEGrhG-CSF for preventing chemotherapy induced neutropenia in patients with breast cancer. Natl Med J China 98:1231-1235

44. Kosaka Y, Rai Y, Masuda N, Takano T, Saeki T, Nakamura S, Shimazaki R, Ito Y, Tokuda Y, Tamura K (2015) Phase III placebo-controlled, double-blind, randomized trial of pegfilgrastim to reduce the risk of febrile neutropenia in breast cancer patients receiving docetaxel/cyclophosphamide chemotherapy. Support Care Cancer 23:1137-1143

45. Vogel CL, Wojtukiewicz MZ, Carroll RR, Tjulandin SA, BarajasFigueroa LJ, Wiens BL, Neumann TA, Schwartzberg LS (2005) First and subsequent cycle use of pegfilgrastim prevents febrile neutropenia in patients with breast cancer: a multicenter, doubleblind, placebo-controlled phase III study. J Clin Oncol 23:11781184

46. Nakov R, Gattu S, Wang J, Velinova M, Schaffar G, Skerjanec A (2018) Proposed biosimilar pegfilgrastim shows similarity in pharmacokinetics and pharmacodynamics to reference pegfilgrastim in healthy subjects. Brit J Clin Pharmacol 84:2790-2801

47. Shi YK, Chen Q, Zhu YZ, He XH, Wang HQ, Jiang ZF, Chang JH, Liu YP, Wang AL, Luo DY, Zhang Y, Ke XY, Li WL, Zhang WJ, Wang XW, Zhang YP, Wang JM, Liu XQ (2013) Pegylated filgrastim is comparable with filgrastim as support for commonly used chemotherapy regimens: a multicenter, randomized, crossover phase 3 study. Anti Cancer Drug 24:641-647

48. Puertolas I, Frutos PA, Alcacera MA, Andres R, Salvador M (2018) Effectiveness of biosimilar filgrastim vs. original granulocyte colony-stimulating factors in febrile neutropenia prevention in breast cancer patients. Eur J Clin Pharmacol 74:315-321

Publisher's note Springer Nature remains neutral with regard to jurisdictional claims in published maps and institutional affiliations. 